\title{
Prediction on Average Price of Commercial Housing in Sichuan Province and Analysis of Influencing Factors Based on Grey System Theory
}

\author{
Jiaying $\mathrm{Li}^{1}$, Enchi Liang ${ }^{1}$, Huaxue Zhuang ${ }^{1}$, Cheng Liu ${ }^{1, *}$ \\ ${ }^{1}$ School of Business, Sichuan Agricultural University, Chengdu, Sichuan 611830, China \\ "Corresponding author. Email: liucheng @ sicau.edu.cn
}

\begin{abstract}
Real estate is of great significance to a country's economy and people's livelihood, and the future price of real estate and its influencing factors can directly reflect the real estate market. This article builds a grey prediction model, referred to as the Gray Model $(1,1)$, based on the average price of commercial housing in Sichuan Province in the past ten years, and predicts the average price of commercial housing in Sichuan in the next three years. Through the grey correlation analysis method, the factors influencing the average price of commercial housing are quantified. Finally, the market of commercial housing in Sichuan Province is summarized, and suggestions are put forward for the healthy, sustainable and high-benefit development of the market.
\end{abstract}

Keywords: commercial housing of Sichuan Province, average price prediction, influencing factors, grey

system theory

\section{INTRODUCTION}

In the middle of April 2010, the State Council issued the "ten new regulations", which opened the curtain of macro-control of China's real estate market. On January 26, 2011, the State Council issued the policy guidance of "eight national regulations" to guide the national real estate market after the "ten national regulations". Subsequently, local governments successively issued local implementation rules to further regulate the real estate market and improve the real estate market regulation. At the beginning of 2015, at the call of the premier of the State Council, the ministry of central finance, ministry of land and resources, development and reform commission, housing and construction and other relevant departments made many voices on the issues of "stabilizing real estate", "invigorating the stock of housing", "financial support", etc. Local governments followed the pace of the new deal and issued favorable policies on the real estate market [1]. For example, in 2016, the people's government of Sichuan Province issued the "24 regulations" on real estate, which stipulated that the pre-sale commercial housing project should disclose the housing source and price in one time within 10 days. In addition, starting from the market supervision of the real estate market, residents' housing credit, tax subsidies and settling purchase, Sichuan Province has adopted different regulation and

CLCN:N945 Document identification code: A control measures such as purchase restriction, loan restriction, notarization and house selection to curb the rapid rise of housing prices [2]. However, with the acceleration of urbanization and the improvement of residents' income level, the original balance of real estate demand has been broken. While the sales area of commercial housing continues to increase, the limited and scarce characteristics of land make the land transfer price far higher than the reasonable level, further promoting the continuous growth of real estate price. Therefore, in view of the above phenomena, it is of great significance to the price prediction and analysis on influencing factor of commercial housing in Sichuan Province.

The analysis of data and the prediction of its future are the major trend of research and exploration by scholars in China and foreign countries, and scholars also put forward many research methods for the analysis and prediction of real estate prices that can affect market fluctuations, and have made some achievements. Zhou Liang and Zhou Zheng forecast the real estate price index by the method of time series [3]; Wang Yanan and Meng Xiaojing use $M$ atlab to establish BP neural network with single hidden layer, and predict the average housing price of Shandong Province in 2014 by training network [4]; Liu Caiyun and Yao Jian use Markov chain analysis to interval the predicted value, improving the reliability of the predicted value [5]; Zhu Bonan uses the grey model to 
study the influencing factors of the real estate price and the prediction [6].

In this paper, according to a variety of research methods and practical factors, grey system theory is adopted to study the data. The grey model can avoid some malicious information and predict the irregular real estate price only according to some information, which is more in line with the reality of incomplete information disclosure. Based on the average price data of commercial housing in Sichuan Province, this paper establishes a grey GM $(1,1)$ model to predict the average price of commercial housing in the next three years, and then calculates the influencing factors of the commercial housing price through the grey correlation analysis model, studies and compares the correlation degree, further identifies the impact on the average price of commercial housing, and finally analyzes the future trend of the market of commercial housing in Sichuan Province.

\section{PREDICTION MODEL OF AVERAGE PRICE OF COMMERCIAL HOUSING IN SICHUAN Province Based ON GM $(\mathbf{1 , 1})$}

The first-order linear grey differential equation model with only one variable is the prediction model most widely used in grey system theory, that is, grey GM $(1,1)$ prediction model.

$$
x^{(0)}(k)+a Z^{(1)}(k)=b,(7)
$$

The above formula is called the shadow equation or whitening equation of the GM $(1,1)$ model.

\section{A. Data selection}

The research object of this article is the average price of commercial housing in Sichuan Province from 2019 to 2018, and the authors use these raw data (unit: yuan / $\mathrm{m} 2$ ) to build a gray prediction model. The specific data is shown in "Table I".

\section{B. $G M(1,1)$ prediction model}

1) Stepwise ratio test

The original sequence should be:

$$
x^{(0)}=(3509,4138,4917.88,5448.82,5498,5597,5475,5762,6217,6987.58)^{T}
$$

According to the formula of stepwise ratio:

$$
\delta^{(0)}(k)=\frac{x^{(0)}(k-1)}{x^{(0)}(k)}, k=2,3, \ldots, n,
$$

It can obtain:

$$
\begin{aligned}
& \qquad \sigma^{0}=(0.8480,0.8414,0.9026,0.9911,0.9823,1.0223,0.9502,0.9268,0.8897)^{T}, \\
& \text { From } \delta^{0}(k) \in\left(e^{\left.-\frac{2}{n+1}, e^{\frac{2}{n+1}}\right)}=(0.833752918,1.199396102), k=2, \ldots 10,\right.
\end{aligned}
$$

the sequence can be modeled as satisfactory GM $(1,1)$.

TABLE I. AVERAGE PRICE OF COMMERCIAL HOUSING IN SICHUAN PROVINCE FROM 2009 TO 2018

\begin{tabular}{|l|l|l|l|l|l|l|l|l|l|l|}
\hline $\mathrm{k}$ & 1 & 2 & 3 & 4 & 5 & 6 & 7 & 8 & 9 & 10 \\
\hline Year & 2009 & 2010 & 2011 & 2012 & 2013 & 2014 & 2015 & 2016 & 2017 & 2018 \\
\hline price & 3509 & 4138 & 4917.88 & 5448.82 & 5498 & 5597 & 5475 & 5762 & 6217 & 6987.58 \\
\hline
\end{tabular}

\section{2) Parameter estimation}

By accumulating the original data $x(0), x^{(1)}=\left(x^{(1)}(1), x^{(1)}(2), \ldots, x^{(1)}(10)\right)^{T}$,

(9) can be obtained:

$\hat{x}^{(1)}=(3509.00,8082.84,12891.19,17946.07,23260.12,28846.62,34719.55,40893.60,47384.19,54207.56,61380.78,68921.77,76849.40)^{T}$

Constructing data matrix B and data vector $\mathrm{YN}$

$$
p=(a, b)^{T}=\left(B^{T} B\right)^{-1} B^{T} Y_{N},
$$

The matrix $\mathrm{B}$ and the original sequence matrix $\mathrm{YN}$ constituted by the accumulative sequence are: 


$$
B=\left[\begin{array}{lr}
-z^{(1)}(2) 1 \\
-z^{(1)}(3) 1 \\
\vdots & \vdots \\
-z^{(1)}(n) 1
\end{array}\right], Y_{N}=\left[\begin{array}{l}
x^{(0)}(2) \\
x^{(0)}(3) \\
\vdots \\
x^{(0)}(n)
\end{array}\right]
$$

Ordering $\mathrm{z}(1)$ be the mean sequence of $\mathrm{x}(1)$,

$$
z^{(1)}=\left(z^{(1)}(2), z^{(1)}(3), \ldots, z^{(1)}(n), z^{(1)}(k)\right)=\frac{1}{2}\left(x^{(1)}(k-1)+x^{(1)}(k)\right) ;
$$

Calculating from the above equation,

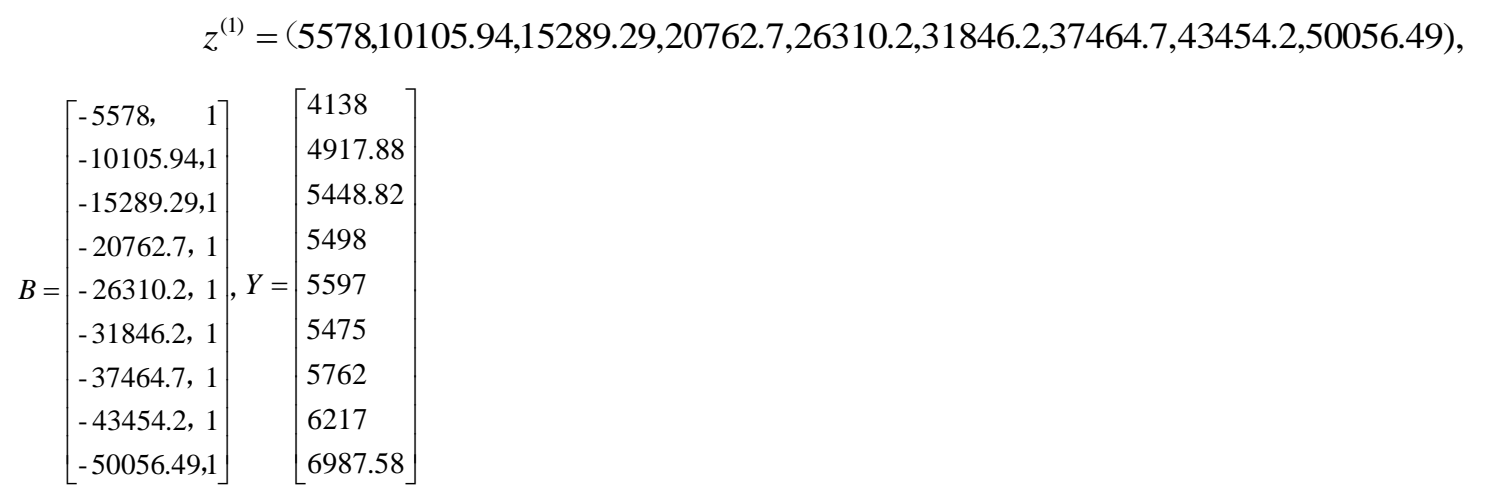

Through MATLAB software, it is to estimate parameters with least square method.

$$
p=(a, b)^{T}=\left(B^{T} B\right)^{-1} B^{T} Y_{N}=\left[\begin{array}{c}
-0.05 \\
4285
\end{array}\right],
$$

So, $\mathrm{a}=-0.05, \mathrm{~b}=4285$ can be obtained.

In the conclusion of this paper, $\mathrm{a}=-0.1$ is consistent with Professor Liu Sifeng's research on the relationship between the period of GM $(1,1)$ model prediction and the range of development coefficient, that is to say, when "- $\mathrm{a} \leq 0.3$, GM $(1,1)$ can be used as the medium and long-term prediction."

According to equation (1), the whitening equation is as follows: ${ }^{(0)}(k)-0.05 z^{(1)}(k)=4285$,

When a is relatively small, the time-response function of the flower-type can be used as the solution of the GM $(1,1)$ model [10], then the above equation is specific as: $\frac{d x^{(1)}}{d t}-0.1 x^{(1)}=4285$,

$\hat{x}^{(1)}=(3509.00,8082.84,12891.19,17946.07,23260.12,28846.62,34719.55,40893.60,47384.19,54207.56,61380.78,68921.77,76849.40)^{T}$

is the obtained estimate of the original sequence. It is necessary to reduce $\mathrm{xxx}$.

It is possible to use $x^{(1)}(1)=x^{(0)}(1)=3509.00$, to obtain the time-response sequence.
Ordering $\mathrm{k}=1,2, \ldots 10$, according to the time response function, the predicted generation number can be listed as:

$$
\hat{x}^{(0)}(k+1)=\hat{x}^{(1)}(k+1)-\hat{x}^{(1)}(k), k=1,2, \ldots, n,
$$




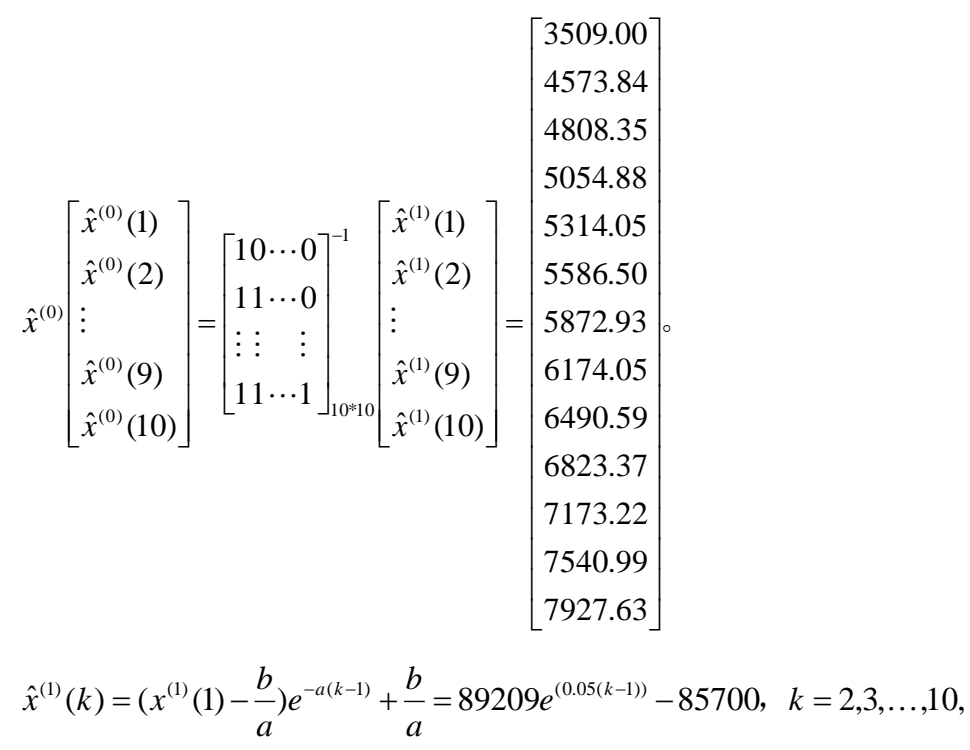

3) Model test

TABLE II. ANALYSIS ON THE ACCURACY OF GM $(1,1)$ MODEL

\begin{tabular}{|c|c|c|c|c|c|}
\hline Serial number & Original value & $\begin{array}{c}\text { Value of } \\
\text { simulation }\end{array}$ & Residual error & $\begin{array}{c}\text { Relative error } \\
(\%)\end{array}$ & Accuracy (\%) \\
\hline 1 & 3509 & 3509 & 0 & 0 & 1 \\
\hline 2 & 4138 & 4573.84 & -435.84 & -10.53 & 89.47 \\
\hline 3 & 4917.88 & 4808.35 & 109.53 & 2.23 & 97.77 \\
\hline 4 & 5448.82 & 5054.88 & 393.94 & 7.23 & 92.77 \\
\hline 5 & 5498 & 5314.05 & 183.95 & 3.35 & 96.65 \\
\hline 6 & 5597 & 5586.50 & 10.5 & 0.19 & 99.81 \\
\hline 7 & 5475 & 5872.93 & -397.93 & -7.27 & 92.73 \\
\hline 8 & 5762 & 6174.05 & -412.05 & -7.15 & 92.85 \\
\hline 9 & 6217 & 6490.59 & -273.59 & -4.40 & 95.60 \\
\hline 10 & 6987.58 & 6823.37 & 164.21 & 2.35 & 97.65 \\
\hline \multicolumn{6}{|c|}{$\begin{array}{l}\text { mean accuracy: } \quad \mathrm{p} 0=95.53 \% \\
\text { Posterior difference ratio } \quad \mathrm{C}=0.2981 \\
\text { Small probability error } \quad \mathrm{P}=1.0000\end{array}$} \\
\hline
\end{tabular}

After verification, the accuracy of the model is qualified, and it can make prediction without residual error correction. Through the above analysis, the price of commercial housing in Sichuan Province will continue to rise. It is predicted that the average price of commercial housing in Sichuan Province in the next three years from 2019-2021 is shown in "Table III".

TABLE III. PREDICTED VALUE OF AVERAGE HOUSING PRICES IN SICHUAN PROVINCE FROM 2019 TO 2021

\begin{tabular}{|l|l|l|l|}
\hline Year & 2019 & 2020 & 2021 \\
\hline $\begin{array}{l}\text { predicted value } \\
\text { (yuan) }\end{array}$ & 7173.215 & 7540.993 & 7927.628 \\
\hline
\end{tabular}

\section{COMPARISON OF INFLUENCING FACTORS OF HOUSING PRICE BASED ON GREY CORRELATION ANALYSIS MODEL}

In the gray correlation analysis [10-11], different factors affect and restrict the system behavior factor $\mathrm{x} 0$. It is necessary to find the gray correlation degree of factor $\mathrm{xi}$ to $\mathrm{x} 0$ to determine the effect of factor $\mathrm{xi}$ on behavior $\mathrm{x} 0$, providing a quantitative measure for the data of the dynamic course.

\section{A. Data selection}

This article selects the 2009-2018 annual data published on the website of the Statistics Bureau of Sichuan Province (see "Table IV"). Due to the difficulty in obtaining the data, according to the influencing factors of actual housing prices and the role 
played by each factor, this article selects the following indicators:

Reference sequence: average price of commercial housing in Sichuan Province (x0),

Comparative sequence: per capita regional GDP (x1), household consumption level (x2), local fiscal revenue (x3), real estate development investment (x4), and year-end permanent population (x5).

TABLE IV. FACTORS AFFECTING THE PRICE OF COMMERCIAL HOUSING IN SICHUAN PROVINCE FROM 2009 TO 2018

\begin{tabular}{|l|l|l|l|l|l|l|}
\hline Year & \multicolumn{1}{|c|}{$\mathbf{X}_{\mathbf{0}}$} & \multicolumn{1}{|c|}{$\mathbf{X}_{\mathbf{1}}$} & \multicolumn{1}{|c|}{$\mathbf{X}_{\mathbf{2}}$} & \multicolumn{1}{|c|}{$\mathbf{X}_{\mathbf{3}}$} & $\mathbf{X}_{\mathbf{4}}$ & \multicolumn{1}{|c|}{$\mathbf{X}_{\mathbf{5}}$} \\
\hline 2009 & 3509 & 17339 & 6863 & 1174.59 & 1588.37 & 8185 \\
\hline 2010 & 4138 & 21182 & 8182 & 1561.67 & 2194.63 & 8045 \\
\hline 2011 & 4917.88 & 26133 & 9903 & 2044.79 & 2819.17 & 8050 \\
\hline 2012 & 5448.82 & 29608 & 11280 & 2421.27 & 3266.4 & 8076 \\
\hline 2013 & 5498 & 32617 & 12485 & 2784.1 & 3853.00 & 8107 \\
\hline 2014 & 5597 & 35128 & 13755 & 3061.07 & 4380.09 & 8140 \\
\hline 2015 & 5475 & 36775 & 14774 & 3355.44 & 4813.03 & 8204 \\
\hline 2016 & 5762 & 40003 & 16013 & 3388.85 & 5282.64 & 8262 \\
\hline 2017 & 6217 & 44651 & 17920 & 3577.99 & 5149.89 & 8302 \\
\hline 2018 & 6987.58 & 48883 & 19834 & 3911.01 & 5697.87 & 8341 \\
\hline
\end{tabular}

\section{B. Data processing}

- Dimensionless initialization

To obtain the initial CString of different dimensional data, it is necessary to nondimensionalize each data of each series, that is, the first number xi (1) divides other numbers xi $(\mathrm{k})$. The results are shown in "Table V". $x_{i}^{\prime}(k)=x_{i}(k) / x_{i}(1), k=1,2, \ldots, m$.

- Difference sequence

$\Delta_{i}(k)=\left|x_{0}^{\prime}(k)-x_{i}^{\prime}(k)\right|, k=1,2, \ldots, n ; i=1,2, \ldots m$.

- finding the maximum difference and minimum difference of two levels

$M=\max \max \Delta_{i}(k), m=\min \min \Delta_{i}(k) ;$

According to the caculation results of "Table VI", $\mathrm{M}=1.684, \mathrm{~m}=0$ can be obtained.

TABLE V. DIMENSIONLESS INFLUENCING FACTORS

\begin{tabular}{|l|c|l|r|r|r|l|}
\hline Year & $\mathbf{x}^{\prime} \mathbf{0}$ & $\mathbf{x}^{\prime} \mathbf{1}$ & $\mathbf{x}^{\prime} \mathbf{2}$ & $\mathbf{x}^{\prime} \mathbf{3}$ & $\mathbf{x}^{\prime} \mathbf{4}$ & \multicolumn{1}{c|}{$\mathbf{x}^{\mathbf{5}}$} \\
\hline 2009 & 1.000 & 1.000 & 1.000 & 1.000 & 1.000 & 1.000 \\
\hline 2010 & 1.179 & 1.222 & 1.192 & 1.330 & 1.382 & 0.983 \\
\hline 2011 & 1.402 & 1.507 & 1.443 & 1.741 & 1.775 & 0.984 \\
\hline 2012 & 1.553 & 1.708 & 1.644 & 2.061 & 2.056 & 0.987 \\
\hline 2013 & 1.567 & 1.881 & 1.819 & 2.370 & 2.426 & 0.990 \\
\hline 2014 & 1.595 & 2.026 & 2.004 & 2.606 & 2.758 & 0.995 \\
\hline 2015 & 1.560 & 2.121 & 2.153 & 2.857 & 3.030 & 1.002 \\
\hline 2016 & 1.642 & 2.307 & 2.333 & 2.885 & 3.326 & 1.009 \\
\hline 2017 & 1.772 & 2.575 & 2.611 & 3.046 & 3.242 & 1.014 \\
\hline 2018 & 1.991 & 2.819 & 2.890 & 3.330 & 3.587 & 1.019 \\
\hline
\end{tabular}

- Finding correlation coefficient and correlation degree

The calculation formula of correlation coefficient is as follows:

$$
r_{i}(k)=\left(\min _{i} \min _{k} \Delta_{i}(k)+\xi \min _{i} \min _{k} \Delta_{i}(k)\right) \div\left(\Delta_{i}(k)+\xi \min _{i} \min _{k} \Delta_{i}(k)\right),
$$

In the equation, $k=1,2, \ldots, n ; i=1,2, \ldots, m \circ \xi=0.5$ 。

The following equation is used to caculate the correlation degree.

$$
R_{i}=\sum_{i=1}^{n} r_{i}(k) / n, k=1,2, \ldots, n 。
$$

When the $\mathrm{R}$ value is close to 1 , it indicates that the factor $\mathrm{X} 1$ in the comparison sequence has a higher influence on the reference sequence factor $\mathrm{x} 0$.

According to the calculation results in "Table VII", $\mathrm{R} 2>\mathrm{R} 1>\mathrm{R} 5>\mathrm{R} 3>\mathrm{R} 4$, that is to say, the order of correlation degree is: residents' consumption level $>$ per capita regional GDP > year-end resident population > local fiscal revenue > local real estate development investment.

From the above results, it can see that the consumption level of residents has a great influence on the price of commercial housing, and there is a certain relationship between them. According to economic theory, when housing prices rise, consumers feel richer, so consumption growth increases. Through the micro verification of the "wealth effect" brought by the rise of housing prices, it can be found that through the variable of house asset value, both the mixed aggregate data and the data of a single year can significantly present the promoting effect of asset appreciation caused by the rise of housing prices on consumption [11]. In the past ten years, China's economy has made rapid development, people's living conditions and national economy have made obvious improvement, the per capita GDP of Sichuan Province has increased nearly five times in ten years, the regional economic development level is good, and people's demand for housing has also increased. With the in-depth development of new urbanization in China, the housing demand of urban residents, especially new citizens, is still strong [12]. How to further improve the urban housing system and achieve the goal of housing for all the people put forward by the 19th National Congress of the Communist Party of China is a major economic and social problem. The policy of accelerating the establishment of multi-body supply, multi-channel 
security, rent and purchase simultaneously, strengthening supporting policies, and making a combination of boxing, etc. proposed by the system construction, promotes the rise of housing prices from the side [13].

TABLE VI. DIMENSIONLESS INFLUENCING FACTORS

\begin{tabular}{|l|l|l|l|l|l|}
\hline Year & \multicolumn{1}{|c|}{$\boldsymbol{\Delta}_{\mathbf{1}}$} & \multicolumn{1}{|c|}{$\boldsymbol{\Delta}_{\mathbf{2}}$} & $\boldsymbol{\Delta}_{\mathbf{3}}$ & $\boldsymbol{\Delta}_{\mathbf{4}}$ & $\boldsymbol{\Delta}_{\mathbf{5}}$ \\
\hline 2009 & 0.000 & 0.000 & 0.000 & 0.000 & 0.000 \\
\hline 2010 & 0.042 & 0.013 & 0.150 & 0.202 & 0.196 \\
\hline 2011 & 0.106 & 0.041 & 0.339 & 0.373 & 0.418 \\
\hline 2012 & 0.155 & 0.091 & 0.509 & 0.504 & 0.566 \\
\hline 2013 & 0.314 & 0.252 & 0.803 & 0.859 & 0.576 \\
\hline 2014 & 0.431 & 0.409 & 1.011 & 1.163 & 0.601 \\
\hline 2015 & 0.561 & 0.592 & 1.296 & 1.470 & 0.558 \\
\hline 2016 & 0.665 & 0.691 & 1.243 & 1.684 & 0.633 \\
\hline 2017 & 0.803 & 0.839 & 1.274 & 1.471 & 0.757 \\
\hline 2018 & 0.828 & 0.899 & 1.338 & 1.596 & 0.972 \\
\hline
\end{tabular}

TABLE VII. GREY CORRELATION COEFFICIENT AND GREY CORRELATION DEGREE

\begin{tabular}{|l|l|l|l|l|l|}
\hline \multicolumn{1}{|c|}{ Year } & \multicolumn{1}{c|}{$\mathbf{r}_{\mathbf{1}}$} & \multicolumn{1}{c|}{$\mathbf{r}_{\mathbf{2}}$} & \multicolumn{1}{c|}{$\mathbf{r}_{\mathbf{3}}$} & \multicolumn{1}{c|}{$\mathbf{r}_{\mathbf{4}}$} & \multicolumn{1}{c|}{$\mathbf{r}_{\mathbf{5}}$} \\
\hline 2009 & 1.000 & 1.000 & 1.000 & 1.000 & 1.000 \\
\hline 2010 & 0.952 & 0.985 & 0.849 & 0.806 & 0.811 \\
\hline 2011 & 0.888 & 0.953 & 0.713 & 0.693 & 0.668 \\
\hline 2012 & 0.845 & 0.903 & 0.623 & 0.626 & 0.598 \\
\hline 2013 & 0.728 & 0.769 & 0.512 & 0.495 & 0.594 \\
\hline 2014 & 0.661 & 0.673 & 0.454 & 0.420 & 0.584 \\
\hline 2015 & 0.600 & 0.587 & 0.394 & 0.364 & 0.601 \\
\hline 2016 & 0.559 & 0.549 & 0.404 & 0.333 & 0.571 \\
\hline 2017 & 0.512 & 0.501 & 0.398 & 0.364 & 0.526 \\
\hline 2018 & 0.504 & 0.484 & 0.386 & 0.345 & 0.464 \\
\hline $\mathrm{R}_{\mathrm{i}}$ & 0.725 & 0.740 & 0.573 & 0.545 & 0.642 \\
\hline
\end{tabular}

\section{Conclusion}

Based on the average price data of commercial housing in Sichuan Province, this paper establishes a grey GM $(1,1)$ prediction model to predict the future price of commercial housing in Sichuan Province, and analyzes the influencing factors of the prediction model. From the prediction results, the price of commercial housing in Sichuan Province increases steadily and step by step. Through the grey correlation analysis of various influencing factors, it can see that the consumption level of residents and GDP per capita in the region have a great impact on the fluctuation of housing prices [14]. Since 2017, a number of cities and prefectures in Sichuan Province have introduced housing purchase subsidy policies, which have stimulated the development of the real estate industry. The real estate sales of each city has entered a relatively good stage. With the support of national policies, it is expected that it will continue to develop steadily in the future. With the analysis of the influencing factors of the real estate price and the prediction of the corresponding results of the real estate price, the real estate price changes greatly, and some factors have a significant impact on it. Therefore, necessary measures can be taken to avoid the risk of the real estate.

\section{References}

[1] Wang Yanan, Meng Xiaojing. Research on Neural Network Housing Price Prediction Based on Momentum BP Algorithm [J]. Journal of Software, 2015, (2): 59-61. DOI: 10.11907 rjdk.1431015. (in Chinese)

[2] Zhou Liang, Zhou Zheng. The Forecast Method Discussion of Real Estate Price Index Based on Time Series [J]. Journal of Harbin Commercial University (Social Science Edition), 2008 (2): 80-83. DOI: 10.3969 / j.issn.1671 -7112.2008.02.023. (in Chinese)

[3] Liu Caiyun, Yao Jian. Real Estate Price Forecasting Model Based on Multiple Factors [J]. Statistics and Decision, 2017, (17): 33-38. DOI: 10.13546 / j.cnki.tjyjc.2017.17.007. (in Chinese)

[4] Zhu Bonan. Research on the influencing factors of commercial housing prices based on grey forecasting and its prediction [J]. Times Finance (Late), 2017, (4): 275-277.

[5] $\mathrm{Hu}$ Shilu. Application method of grey system theory in forecasting economic indicators $[\mathrm{J}]$. Economic Outlook on the Bohai Rim, 2018 (10): 165-166. (in Chinese)

[6] Meng Ying, Rao Congjun. Forecasting and analysis of influencing factors of the average price of commercial housing in Hubei Province based on grey system theory [J]. Journal of Hubei Institute of Technology, 2018, 38 (03): 43-47. (in Chinese)

[7] Yan Xiangrui. Analysis and forecast of real estate prices in China [D]. Central China Normal University, 2015. (in Chinese)

[8] Yan Ling. Analysis on the influencing factors of residents consumption level [J]. Business, 2016 (02): 108. (in Chinese)

[9] Qiu Chengfeng. Empirical test of the housing price fluctuations on household consumption $[\mathrm{J}]$. Journal of Commercial Economics, 2019 (07): 180-182. (in Chinese)

[10] Shu Jiaxian, Wu Hangyu. Research on the Factors Influencing the Price of Real Estate based on Gray System [J]. Journal of Harbin Normal University (Social Science), 2017, 8 (01): 86-89. (in Chinese)

[11] Siqin. Application of grey forecasting system in the forecast of sales of commercial housing for urban residents [J]. Statistics and Decision, 2004 (12): 163-164. (in Chinese)

[12] Sun Shouxuan, Wu Yan, Pan Yacheng, Zhang Hongwei. Analysis and forecast of commercial housing prices based on the gray system GM $(2,1)$ model: A case study of major cities in Hainan Province [J]. Computer Knowledge and Technology, 2019,15 (06): 191-192 + 197. (in Chinese)

[13] Sun Xuefei. A Method for Forecasting Real Estate Market Price Based on Grey System Theory [D]. Northeastern University, 2007. (in Chinese)

[14] Liu Xingye. Prediction of Harbin commercial housing transaction volume based on grey system theory $[\mathrm{C}]$. Wuhan University, James Madison University, American Scientific Publishing House: Proceedings of International Conference on Engineering and Business Management (EBM2010), 2010: 3813-3815. (in Chinese) 